\title{
Natural leaf packs and invertebrates in a tropical stream: Is there a functional relationship?
}

\author{
Hiranthi Walpola ${ }^{1}$, Maria Leichtfried ${ }^{2}$ and Leopold Füreder ${ }^{1}$ \\ ${ }^{1}$ River Ecology and Conservation, Institute of Ecology, University of Innsbruck, Technikerstr. 25, \\ A-6020 Innsbruck, Austria \\ ${ }^{2}$ Institute for Limnology of the Austrian Academy of Sciences, Mondseestr. 9, A-5310 Mondsee, \\ Austria
}

*Correspondence (maria.leichtfried@pchnet.at)

ID

https://orcid.org/0000-0002-5793-7270

\begin{abstract}
Naturally occurring leaf packs in five sites along the elevation gradient in Eswathu Oya stream in Sri Lanka were sampled and analysed for species composition of leaves and benthic macroinvertebrates. Eswathu Oya is a perennial, low order, mountain stream in the wet climatic zone of Sri Lanka. Leaves of only five species of plants were found in all sites - Hevea brasiliensis, Ochlandra stridula, Alstonia macrophylla, Terminalia arjuna and Melia azedarach. In each sampling site Hevea brasiliensis and Ochlandra stridula leaves were found in higher abundance. The contribution of other leaves varied with the site. Diptera larvae of the family Chironomidae, were the dominant group of leaf colonizing animals. The relative abundance of Chironomidae decreased along the elevation gradient in the down-stream. Gathering Collectors (GC) were the dominant functional feeding group (FFG) found in all leaf packs, but their abundance decreased along the downstream elevation gradient. Shredders were not present, as reported from some other tropical streams. Predators and Scrapers were increased along the downstream gradient. Filtering Collectors and Pierce-Herbivores did not show a clear pattern. The study documents that macro invertebrate communities responded to change in water quality, availability of leaves and their nutritional quality along the elevation gradient in Eswathu Oya, Sri Lanka.
\end{abstract}

Keywords: Lotic ecosystems, Longitudinal gradient, Functional feeding groups, Tropical streams

\section{INTRODUCTION}

Allochthonous input of organic matter as a source of nutrients can influence the structure and function of food webs in streams (Polis and Hurd, 1996; Anderson and Polis, 1998; Leichtfried, 2007). Different physical, chemical and biological processes in the stream contribute to the decomposition of organic matter, mineralizing them to elements, which are released to the stream to be available for micro-organisms and biofilms (Swift et al. 1979; Gessnnet et al., 1999). These processes can increase the production of primary consumers; thus creating more food for higher trophic levels (Strong, 1992; Huxel and McCann, 1998). Feeding activities and decomposition stimulated by these invertebrates vary with time and space. Invertebrates are important in the decomposition process, through accelerating it by fragmenting the organic matter into smaller pieces, thus increasing the surface area available for biofilms and microbial activity (Graça, 2001; Leichtfried, 2007). Shredders were often considered as the dominant determinants of the decomposition process of allochthonous organic matter in small temperate streams Dobson et al., 2002). However, the role of invertebrate organisms in the decomposition has not been satisfactorily investigated in tropical streams (Dobson et al., 2002; Mathuriau and Chauver, 2002).

Decomposition processes in natural ecosystems are also influenced by differences in temperature, composition of the organic matter, and structure of decomposer assemblages (Swift et al., 1979; Aerts, 1997; Royer and Minshall, 2003; Hättenschwiler and Gasser, 2005). Litter consumption by invertebrates may fluctuate in response to litter availability and palatability (Cummins et al., 1989), leaf structure and chemistry (Campbell and Fuchshuber, 1995; Findlay et al., 1996), microbial conditioning, 


\section{Hiranthi Walpola et al.}

development of biofilms (Bärlocher and Kendrick, 1975) and other parameters.

Some studies report that in streams, the composition of macro invertebrate assemblages colonizing leaf bags differs between tropical and temperate systems, with shredders as the dominant group in decomposing leaf litter in temperate regions (Vannote et al., 1980; Graça, 2001). In tropical regions, shredders are often not the dominant colonizing group (Rosemond et al., 1989; Dudgeon and Wu, 1999; Dudgeon, 2000; Dobson et al., 2002), but some other studies report the opposite (e.g., Pearson et al., 1989; Cheshire et al., 2005; Cummins et al., 2005).

Variations in aquatic habitats such as streams have been reviewed by Webster and Benfield (1986) and Royer and Minshall (2003), who included differences due to physical and chemical factors (Chergui and Pattèe, 1988; Irons et al., 1994; Subrkropp and Chauvet, 1995; Dangles et al., 2004), type of riparian forest and land use patterns (Whiles and Wallace, 1997; Sponseller and Benfield, 2001; Danger and Robson, 2004), and the effects of litter quality (Petersen and Cummins, 1974; Webster and Benfield, 1986) and macro invertebrates (Wallace and Webster, 1996; Rosmend et al., 1998; Graça, 2001; Wright and Covich, 2005). Large differences were found among experimental treatments, where macro invertebrate abundance was manipulated (Graça, 2001), with some studies showing higher decomposition rates, when macro invertebrates were present (Petersen and Cummins, 1974; Bradford et al., 2002). Other studies did not show any significant effects due to macro invertebrates (Rosemond et al., 1998; Stockley et al., 1998) or an interaction with leaf quality (Vanconcelos and Laurance, 2005; Wright and Covich, 2005). Therefore, leaf litter decomposition processes are strongly influenced by differences in climatic conditions, habitat types, and by effects of different functional feeding groups (FFGs) of decomposer assemblages.

Macro invertebrate community structure and function is influenced by a complex of abiotic and biotic factors that interact over a range of spatial and temporal scales (Richards et al., 1997). Abiotic factors like the local water flow regime (e.g., Brown and Brussock, 1991), substrate composition and porosity (Wood and Armitage, 1997), substrate stability (Death, 1995), and the presence of large wood (Benke et al., 1984) play an important role in structuring benthic communities, but comparatively little information on these subjects is available from tropical areas.

Very little attention has been given to study invertebrates associated with the leaf litter decomposition process in tropical countries, especially in South East Asia, in contrast to Hong Kong, where several studies are published (e.g., Li and Dudgeon, 2009). Most studies of the benthic fauna in Sri Lanka's streams were taxonomic or faunistic (e.g., Wijenayake et al., 2001).

The aim of this study was (i) to evaluate the natural density and type of senescent leaves in a tropical stream along a longitudinal gradient, (ii) to estimate potential habitat and food qualities for macro invertebrates in their natural environment, and (iii) to analyse potential functional relationships between leaves and invertebrates.

\section{MATERIALS AND METHODS}

\section{Study area}

The investigation was carried out in the Eswathu Oya, a low order stream in the wet climatic zone of Sri Lanka (Fig. 1). The river drains a hilly, cascading landscape and runs into the Kelani River, the second largest river (144 km long) in Sri Lanka. The catchment is geologically dominated by the charnockite series in this area. Due to the topology of the catchment and the fluctuation of water level, pools and riffles are developed in Eswathu Oya stream, which provide the basic niche structure for the benthic invertebrates. Eswathu Oya has large consecutive pools and riffles through the natural cascade in the landscape. Five sites along the longitudinal gradient were selected for sampling. The temperature, $\mathrm{pH}$, electrical conductivity, water velocity and profiles were recorded in order to calculate water discharge in pools in each site. 


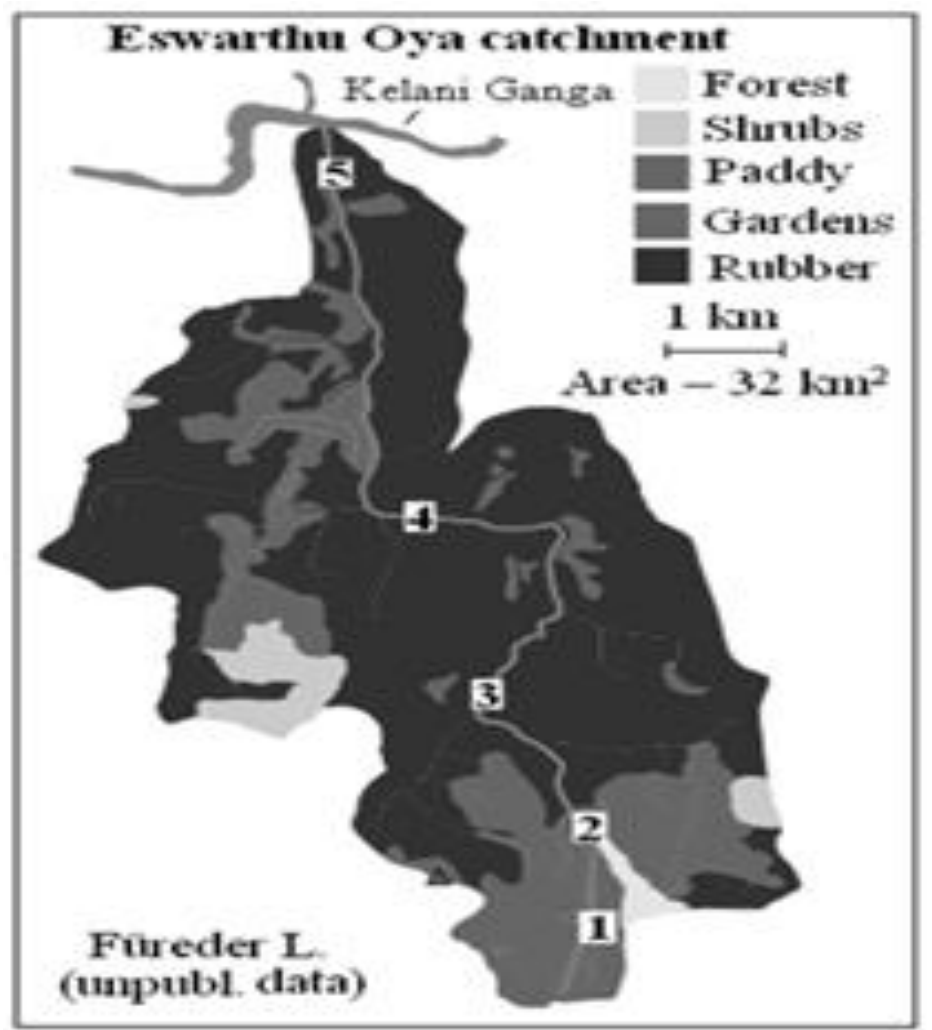

Fig 1 Study site locations $(1-5)$ in Eswathu Oya

\section{Sampling method}

Five random samples of natural leaf packs (fallen/ senescent leaves in the bottom of the stream) were collected from each site using the Dip net method (100 $\mu \mathrm{m}, 20 \times 20 \mathrm{~cm}^{2}$ sampling area). The species composition of the plant leaves in the natural leaf packs was determined in the lab and benthic macro invertebrates were separated and identified up to the best possible taxonomic level. The benthic macro invertebrates were classified into functional feeding groups (FFGs) according to Merritt and Cummins (1996), Dudgeon (1999) and Fernando and Weerawardhane (2002).

\section{RESULTS}

A total of 25 natural leaf packs (in total 500 leaves) were analyzed from five sites along the longitudinal gradient (Fig. 1) of Eswathu Oya stream. The temperature showed slight increment, the dissolved oxygen and electrical conductivity shows also a slight increment towards downstream. The slightly acidic $\mathrm{pH}$ remains throughout the sites. The discharge increased 15 times from headwaters to downstream (Table 1).

Altogether, 29 species of plant leaves were found in the leaf packs. Leaves of plant species such as Hevea brasilensis, Ochlandra stridula, Alstonia macrophylla, Terminalia arjuna, Melia azedarach and Artocarpus nobilis occurred in all sampling site. Ochlandra stridula and Hevea brasiliensis were representing as the most dominant plant leaves in leaf packs and found in head waters to downstream sites (Table 2). The mean quantitative occurrence of different species in the leaf packs is shown in Table 31 
Table 1 Surface water characteristics of the investigated five sites in longitudinal profile of Eswathu Oya, measured during sampling (mean $\pm \mathrm{SD}, \mathrm{n}=5)$.

\begin{tabular}{llllll}
\hline \multirow{2}{*}{ Parameter } & Sites & & & & \\
\cline { 2 - 6 } & $\mathbf{1}$ & $\mathbf{2}$ & $\mathbf{3}$ & $\mathbf{4}$ & $\mathbf{5}$ \\
\hline Temp. $\left({ }^{\circ} \mathrm{C}\right)$ & $25.6 \pm 0.6$ & $25.9 \pm 0.8$ & $26.2 \pm 0.3$ & $26.4 \pm 0.2$ & $26.8 \pm 0.4$ \\
$\mathrm{pH}$ & $6.1 \pm 0.2$ & $6.1 \pm 0.1$ & $6.2 \pm 0.4$ & $6.1 \pm 0.5$ & $5.9 \pm 0.8$ \\
Dissolve Oxygen $\left(\mathrm{mg} \mathrm{l}^{-1}\right)$ & $6.4 \pm 0.1$ & $6.8 \pm 0.6$ & $6.9 \pm 0.4$ & $6.9 \pm 0.3$ & $7.1 \pm 0.5$ \\
Discharge $\left(1 \mathrm{sec}^{-1}\right)$ & $13.06 \pm 5.2$ & $30.93 \pm 7.3$ & $65.49 \pm 5.9$ & $85.49 \pm 89$ & $209.12 \pm 10.5$ \\
Conductivity $\left(\mu \mathrm{S}_{20} \mathrm{~cm}^{-1}\right)$ & $29.2 \pm 0.1$ & $31.2 \pm 0.3$ & $32.0 \pm 0.2$ & $34.2 \pm 0.2$ & $33.2 \pm 0.1$ \\
\hline
\end{tabular}

Table 2 Leaf species composition of sampled leaf packs in Eswathu Oya.

\begin{tabular}{|c|c|c|c|c|c|}
\hline Family & Species & Common name & Source & Toughness & Sites \\
\hline Caricaceae & Carica papaya & Papaw & introduced & soft & 5 \\
\hline Annonaceae & Annona glabra & Wal Anoda & introduced & medium & 4,5 \\
\hline Dilleniaceae & Dillenia retusa & Godapara & endemic & moderate & 4,5 \\
\hline Dipterocarpaceae & Dipterocarpus zeylanicus & Hora-Gass & endemic & moderate & 4,5 \\
\hline Elaeocarpaceae & Elaeocarpus serratus & Weralu & native & medium & 4,5 \\
\hline Icacinaceae & Stemonurus apicalis & Uru Honda & endemic & medium & 4,5 \\
\hline Leguminisae & Cassia spectabilis & Kaha Kona & introduced & soft & 4,5 \\
\hline Moraceae & Artocarpus altilis & Bread Fruit & introduced & rough & 4,5 \\
\hline Palmae & Caryota urens & Kitul Palm & native & rough & 4,5 \\
\hline Combretaceae & Terminalia catappa & Indian Almond & introduced & rough & $2,3,5$ \\
\hline Anacardiaceae & Mangifera indica & Mango & introduced & medium & $3,4,5$ \\
\hline Anacardiaceae & Spondias dulcis & Ambarella & introduced & soft & $3,4,5$ \\
\hline Apocynaceae & Alstonia scholaris & Ruk Attana & native & medium & $3,4,5$ \\
\hline Euphorbiaceae & Macaranga indica & Bu Kenda & native & soft & $3,4,5$ \\
\hline Leguminisae & Caesalpinia pulcherrima & Paradise Flower & introduced & soft & $3,4,5$ \\
\hline Malvaceae & Hibiscus rosasinensis & Wada Mal & introduced & soft & $3,4,5$ \\
\hline Palmae & Areca catechu & Betel Nut Palm & introduced & rough & $3,4,5$ \\
\hline Palmae & Cocos nucifera & Coconut Palm & introduced & rough & $3,4,5$ \\
\hline Rutaceae & Citrus aurantiifolia & Lime & introduced & rough & $3,4,5$ \\
\hline Rutaceae & Citrus limon & Lemon & introduced & medium & $3,4,5$ \\
\hline Clusiaceae & Mesua nagassarium & Ceylon Ironwood & native & soft & $2,3,4,5$ \\
\hline Euphorbiaceae & Ptychopyxis thwaitesii & Wal Rambutan & endemic & rough & $2,3,4,5$ \\
\hline Moraceae & Artocarpus heterophyllus & Jak & endemic & rough & $2,3,4,5$ \\
\hline Apocynaceae & Alstonia macrophylla & $\begin{array}{l}\text { Alstonia, Hawari } \\
\text { nuga }\end{array}$ & exotic & soft & $1,2,3,4,5$ \\
\hline Combretaceae & Terminalia arjuna & Kumbuk & native & moderate & $1,2,3,4,5$ \\
\hline Euphorbiaceae & Hevea brasiliensis & Rubber & introduced & moderate & $1,2,3,4,5$ \\
\hline Meliaceae & Melia azedarach & Ceylon Mahogani & endemic & tough & $1,2,3,4,5$ \\
\hline Moraceae & Artocarpus nobilis & Wal Del & endemic & rough & $1,2,3,4,5$ \\
\hline Poaceae & Ochlandra stridula & Bamboo & native & rough & $1,2,3,4,5$ \\
\hline
\end{tabular}


Hiranthi Walpola et al.

Table 3 Quantity of leaf species in sampled leaf packs

\begin{tabular}{|c|c|c|c|c|c|}
\hline \multirow{2}{*}{ Leaf Species } & \multicolumn{5}{|c|}{ Site / Abundance (mean \pm SD) } \\
\hline & 1 & 2 & 3 & 4 & 5 \\
\hline Alstonia macrophylla & $1 \pm 0$ & $2 \pm 0$ & $1 \pm 0$ & $1.3 \pm 0.57$ & $1.5 \pm 0.70$ \\
\hline Alstonia scholaris & & & $1 \pm 0$ & $1 \pm 0$ & $1 \pm 0$ \\
\hline Annona glabra & & & & $1 \pm 0$ & $1 \pm 0$ \\
\hline Areca catechu & & & $1 \pm 0$ & $1 \pm 0$ & $1 \pm 0$ \\
\hline Artocarpus altilis & & & & $1 \pm 0$ & $1 \pm 0$ \\
\hline $\begin{array}{l}\text { Artocarpus } \\
\text { heterophyllus }\end{array}$ & & $1 \pm 0$ & $1 \pm 0$ & $1 \pm 0$ & $1 \pm 0$ \\
\hline Artocarpus nobilis & $1 \pm 0$ & $1 \pm 0$ & $1 \pm 0$ & $1 \pm 0$ & $1 \pm 0$ \\
\hline $\begin{array}{l}\text { Caesalpinia } \\
\text { pulcherrima }\end{array}$ & & & $1 \pm 0$ & $6.4 \pm 1.14$ & $1 \pm 0$ \\
\hline Carica papaya & & & & & $1 \pm 0$ \\
\hline Caryota urens & & & & $1 \pm 0$ & $1 \pm 0$ \\
\hline Cassia spectabilis & & & & $1 \pm 0$ & $1 \pm 0$ \\
\hline Citrus aurantiifolia & & & $1 \pm 0$ & $1 \pm 0$ & $1 \pm 0$ \\
\hline Citrus limon & & & $1 \pm 0$ & $1 \pm 0$ & $1 \pm 0$ \\
\hline Cocos nucifera & & & $1 \pm 0$ & $1 \pm 0$ & $1 \pm 0$ \\
\hline Dillenia retusa & & & & $1 \pm 0$ & $1 \pm 0$ \\
\hline $\begin{array}{l}\text { Dipterocarpus } \\
\text { zeylanicus }\end{array}$ & & & & $1.5 \pm 0.70$ & $1 \pm 0$ \\
\hline Elaeocarpus serratus & & & & $1 \pm 0$ & $1 \pm 0$ \\
\hline Hevea brasiliensis & $6.4 \pm 1.14$ & $8.8 \pm 3.27$ & $7.2 \pm 1.09$ & $6.4 \pm 1.67$ & $6.8 \pm 1.92$ \\
\hline Hibiscus rosa sinensis & & & $1 \pm 0$ & $1 \pm 0$ & $1 \pm 0$ \\
\hline Macaranga indica & & & $1 \pm 0$ & $1 \pm 0$ & $1 \pm 0$ \\
\hline Mangifera indica & & & $1 \pm 0$ & $1 \pm 0$ & $1 \pm 0$ \\
\hline Melia azedarach & $2.75 \pm 0.95$ & $1.6 \pm 0.57$ & $1.6 \pm 0.57$ & $1.3 \pm 0.57$ & $1 \pm 0$ \\
\hline Mesua nagassarium & & $1 \pm 0$ & $1 \pm 0$ & $1 \pm 0$ & $1.3 \pm 0.57$ \\
\hline Ochlandra stridula & $6.2 \pm 1.48$ & $7.2 \pm 5.01$ & $5 \pm 1.58$ & $5 \pm 1.22$ & $2.6 \pm 1.94$ \\
\hline Ptychopyxis thwaitesii & & $1 \pm 0$ & $1 \pm 0$ & $1 \pm 0$ & $1 \pm 0$ \\
\hline Spondias dulcis & & & $1 \pm 0$ & $1 \pm 0$ & $1 \pm 0$ \\
\hline Stemonurus apicalis & & & & $1 \pm 0$ & $1 \pm 0$ \\
\hline Terminalia arjuna & $2.33 \pm 0.57$ & $2 \pm 1$ & $2 \pm 1$ & $1.6 \pm 0.57$ & $1.25 \pm 0.5$ \\
\hline Terminalia catappa & & $1.5 \pm 0.70$ & $1.5 \pm 0.70$ & & $1.5 \pm 0.70$ \\
\hline
\end{tabular}

In total, 52 operational taxonomic units (OTUs) were identified among the macroinvertebrates, belonging to 36 families and seven classes/orders. The major groups were Diptera, Coleoptera, Ephemeroptera and Trichoptera. The highest number of families and OTU (17) was reported from Diptera. Trichoptera representing eight families and nine OTUs; Coleoptera with four families and eight OTUs; Ephemeroptera with five families and six OTUs; Odonata with three families and three OTUs and Hymenoptera with three families and three OTUs. Plecoptera were present with two families and two OTUs; and Mollusca with one family and one OTU (Table 4). 


\section{Hiranthi Walpola et al.}

Table 4 Invertebrates colonizing natural leaf packs sampled in a longitudinal pattern in Eswathu Oya.

\begin{tabular}{|c|c|c|c|c|c|c|}
\hline \multirow{2}{*}{$\begin{array}{l}\text { Order/ } \\
\text { Class / Family }\end{array}$} & \multicolumn{4}{|c|}{ Site / Abundance $($ mean \pm SD) } & \multirow[b]{2}{*}{4} & \multirow[b]{2}{*}{5} \\
\hline & OTU & 1 & 2 & 3 & & \\
\hline \multicolumn{7}{|l|}{ Diptera } \\
\hline Simuliidae & 2 & $8.9 \pm 5.7$ & $16.8 \pm 9.6$ & $14.8 \pm 4.2$ & $24.0 \pm 7.0$ & $31.4 \pm 11.2$ \\
\hline Empididae & 1 & $0.9 \pm 1.7$ & $1.0 \pm 0.7$ & $1.6 \pm 1.1$ & $2.0 \pm 0.7$ & $3.8 \pm 1.3$ \\
\hline Atheceridae & 1 & $1.5 \pm 1.4$ & $1.4 \pm 1.3$ & $3.0 \pm 1.8$ & $4.0 \pm 2.0$ & $5.6 \pm 3.8$ \\
\hline Tanypodinae & 1 & $0.3 \pm 0.5$ & $1.8 \pm 1.4$ & $1.4 \pm 1.5$ & $3.4 \pm 2.1$ & $5.2 \pm 2.7$ \\
\hline Tipulidae & 1 & $1.2 \pm 1.5$ & $1.0 \pm 1.4$ & $1.6 \pm 0.9$ & $2.4 \pm 1.5$ & $4.8 \pm 1.9$ \\
\hline Ceratopogonidae & 1 & $3.4 \pm 3.6$ & $5.6 \pm 2.7$ & $6.0 \pm 1.9$ & $10.0 \pm 1.5$ & $14.6 \pm 5.8$ \\
\hline Tipulidae pupa & 1 & $0.8 \pm 1.7$ & $1.6 \pm 1.1$ & $1.8 \pm 1.3$ & $3.2 \pm 1.3$ & $3.0+3.5$ \\
\hline Chironomid.pupa & 1 & $2.2 \pm 1.7$ & $4.2 \pm 2.2$ & $6.4 \pm 2.7$ & $4.8 \pm 3.0$ & $6.8 \pm 5.5$ \\
\hline Chironomidae & 8 & $61.9 \pm 47.4$ & $100.6 \pm 21.5$ & $114.8 \pm 29.6$ & $112.2 \pm 24.9$ & $163.2 \pm 27.1$ \\
\hline \multirow[t]{3}{*}{ total } & 17 & $111.4 \pm 20.9$ & $134.0 \pm 32.5$ & $151.4 \pm 32.1$ & $166.0 \pm 21.1$ & $238.4 \pm 57.7$ \\
\hline & & $H^{\prime}=2.01 \pm 0.21$ & $H^{\prime}=2.15 \pm 0.21$ & $\mathrm{H}^{\prime}=2.21 \pm 0.12$ & $\mathrm{H}^{\prime}=2.37 \pm 0.18$ & $\mathrm{H}^{\prime}=2.32 \pm 0.10$ \\
\hline & & $E=0.78 \pm 0.04$ & $E=0.81 \pm 0.05$ & $E=0.80 \pm 0.03$ & $E=0.84 \pm 0.05$ & $E=0.82 \pm 0.03$ \\
\hline \multicolumn{7}{|l|}{ Trichoptera } \\
\hline Leptoceridae & 1 & $2.0 \pm 2.1$ & $1.2 \pm 1.3$ & $3.6 \pm 3.0$ & $4.6 \pm 1.9$ & $6.6 \pm 2.8$ \\
\hline Lepidostomatidae & 1 & $0.3 \pm 0.3$ & $0.2 \pm 0.4$ & $0.8 \pm 1.3$ & $2.0 \pm 1.2$ & $3.8 \pm 2.3$ \\
\hline Ecnomidae & 1 & $0.2 \pm 0.3$ & $0.4 \pm 0.5$ & 0 & $0.6 \pm 0.5$ & $0.8 \pm 1.0$ \\
\hline Hydroptilidae & 1 & $2.2 \pm 2.2$ & $1.8 \pm 0.4$ & $5.4 \pm 2.8$ & $3.8 \pm 2.1$ & $5.8 \pm 2.1$ \\
\hline Hydropsychidae & 1 & $1.4 \pm 1.6$ & $1.0 \pm 0.7$ & $3.2 \pm 2.5$ & $1.4 \pm 1.3$ & $3.0 \pm 1.5$ \\
\hline Hydropsychidae & 1 & $0.9 \pm 1.6$ & $0.6 \pm 0.8$ & $0.2 \pm 0.4$ & $1.6 \pm 1.6$ & $0.8 \pm 0.4$ \\
\hline Psychomyiidae & 1 & $0.1 \pm 0.3$ & $0.8 \pm 1.7$ & $0.6 \pm 1.3$ & $2.0 \pm 1.4$ & $1.0 \pm 1.0$ \\
\hline Xiphocentronidae & 1 & 0.0 & $0.4 \pm 0.5$ & $1.0 \pm 1.7$ & $1.6 \pm 2.3$ & $0.6 \pm 0.8$ \\
\hline Helicopsychidae & 1 & 0.0 & $0.4 \pm 0.8$ & $1.8 \pm 2.9$ & $2.0 \pm 1.4$ & $3.0 \pm 1.5$ \\
\hline \multirow[t]{3}{*}{ total } & 9 & $7.0 \pm 6.3$ & $6.8 \pm 4.6$ & $16.6 \pm 8.6$ & $19.6 \pm 5.6$ & $25.4 \pm 6.5$ \\
\hline & & $\mathrm{H}^{\prime}=0.81 \pm 0.77$ & $\mathrm{H}^{\prime}=1.23 \pm 0.54$ & $\mathrm{H}^{\prime}=1.19 \pm 0.50$ & $\mathrm{H}^{\prime}=1.71 \pm 0.40$ & $\mathrm{H}^{\prime}=1.76 \pm 0.14$ \\
\hline & & $\mathrm{E}=0.51 \pm 0.47$ & $E=0.88 \pm 0.17$ & $E=0.47 \pm 0.07$ & $E=0.79 \pm 0.22$ & $\mathrm{E}=0.89 \pm 0.03$ \\
\hline \multicolumn{7}{|l|}{ Coleoptera } \\
\hline Psephenidae & 1 & $1.10 \pm 1.5$ & $2.4 \pm 1.1$ & $3.6 \pm 1.9$ & $4.4 \pm 3.2$ & $3.8 \pm 2.3$ \\
\hline Elmidae & 4 & $4.67 \pm 4.3$ & $9.4 \pm 3.4$ & $17.4 \pm 2.3$ & $24.0 \pm 4.5$ & $22.6 \pm 9.5$ \\
\hline Scirtidae & 2 & $4.57 \pm 4.8$ & $13.2 \pm 5.0$ & $28.6 \pm 7.3$ & $23.0 \pm 4.4$ & $25.0 \pm 5.0$ \\
\hline Hydrophilidae & 1 & $0.95 \pm 1.6$ & $1.8 \pm 1.4$ & $5.0 \pm 2.1$ & $6.6 \pm 2.6$ & $5.6 \pm 1.6$ \\
\hline total & 8 & $2.8 \pm 3.1$ & $6,7 \pm 2.7$ & $13.7 \pm 3.4$ & $14.5 \pm 3.7$ & $14.3 \pm 4.6$ \\
\hline \multicolumn{7}{|l|}{ Ephemeroptera } \\
\hline Leptophlebiidae & 2 & $1.2 \pm 1.5$ & $2.6 \pm 2.7$ & $4.4 \pm 3.6$ & $11.4 \pm 9.3$ & $10.8 \pm 5.8$ \\
\hline Ephemerellidae & 1 & $0.5 \pm 0.7$ & $2.4 \pm 2.1$ & $1.8 \pm 1.4$ & $4.6 \pm 3.2$ & $4.6 \pm 1.8$ \\
\hline Caenidae & 1 & $1.4 \pm 1.6$ & $2.0 \pm 1.2$ & $2.2 \pm 1.4$ & $2.6 \pm 2.7$ & $3.4 \pm 1.5$ \\
\hline Siphlonuridae & 1 & $0.8 \pm 1.7$ & $1.6 \pm 1.6$ & $1.2 \pm 1.3$ & $1.8 \pm 1.4$ & $2.0 \pm 1.0$ \\
\hline Baetidae & 1 & $2.0 \pm 1.8$ & $4.4 \pm 2.0$ & $7.8 \pm 0.8$ & $9.4 \pm 3.4$ & $8.0 \pm 3.7$ \\
\hline \multirow[t]{3}{*}{ total } & 6 & $5.2 \pm 3.0$ & $13.0 \pm 7.5$ & $17.4 \pm 7.1$ & $29.8 \pm 16.9$ & $28.8 \pm 10.1$ \\
\hline & & $\mathrm{H}^{\prime}=0.88 \pm 0.61$ & $\mathrm{H}^{\prime}=1.36 \pm 0.34$ & $\mathrm{H}^{\prime}=1.24 \pm 0.49$ & $\mathrm{H}^{\prime}=1.34 \pm 0.53$ & $H^{\prime}=1.59 \pm 0.10$ \\
\hline & & $\mathrm{E}=0.69 \pm 0.39$ & $E=0.94 \pm 0.06$ & $\mathrm{E}=0.81 \pm 0.14$ & $\mathrm{E}=0.84 \pm 0.14$ & $E=0.90 \pm 0.03$ \\
\hline
\end{tabular}

The abundance, diversity and evenness of the decreased downstream along the longitudinal benthic macro invertebrates in natural leaf packs are shown in Table 4. Total abundances of benthic macro invertebrates increased steadily in a longitudinal pattern (Fig. 2). Chironomidae larvae were the most dominating group of leaf colonizing animals in all sites but their relative abundance gradient. Coleoptera were the second largest group present in the leaf packs. Their relative abundance increased along the stream except at the lowest site 5. Relative proportions of other groups were low without such clear distribution patterns (Fig. 3). 


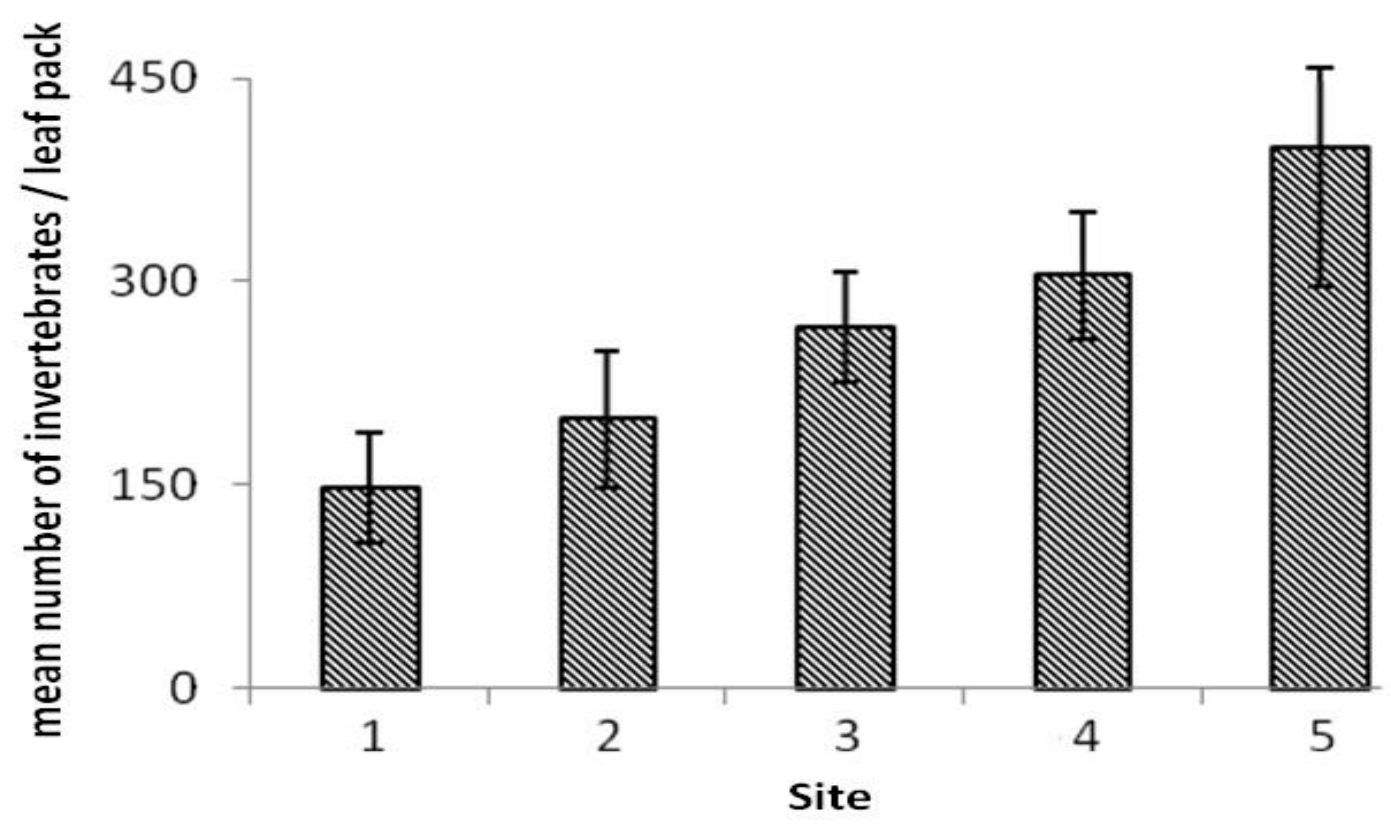

Fig 2 Longitudinal distribution of colonizing invertebrates in natural leaf packs from Eswathu Oya; means $\pm S D, n=5$. Site 1 is the headwater site and site 5 is located fifteen $\mathrm{km}$ downstream.

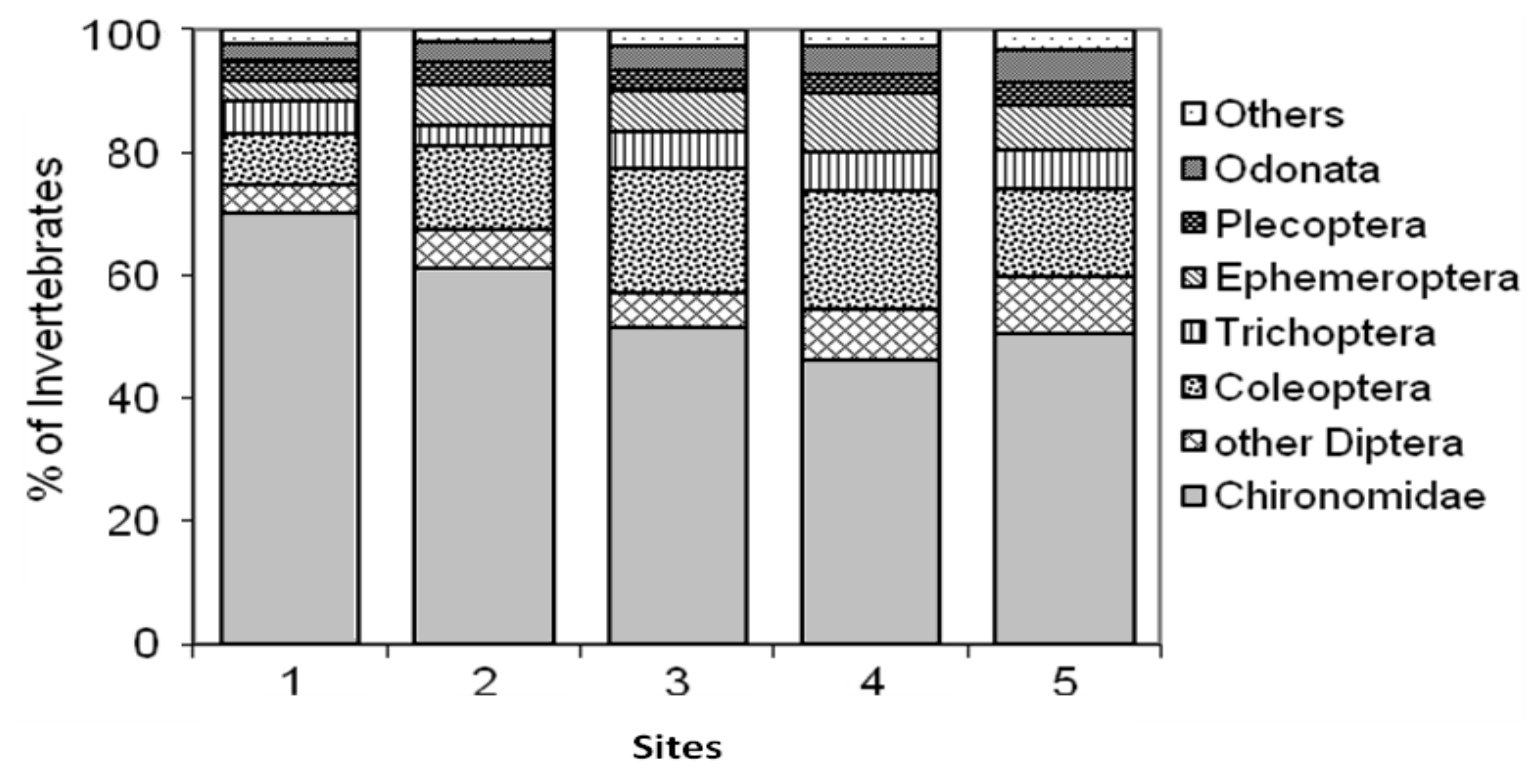

Fig 3 Relative longitudinal taxa distribution of leaf packs colonizing invertebrates.

Five functional feeding groups (FFGs) were determined among the benthic macro invertebrates namely gathering collectors, filtering collectors, pierce herbivores, scrapers and predators. The shredders were not found in any of the leaf packs (Fig. 4). Gathering collectors were the dominant 


\section{Hiranthi Walpola et al.}

functional feeding group among all of the sites and their proportion decreased along the longitudinal gradient. Proportions of predators and scrapers increased along the downstream sites. Filtering Collectors and Pierce-Herbivores did not show a clear pattern. The mean benthic macro invertebrate variety and the Shannon-Wiener $\left(\mathrm{H}^{`}\right)$ diversity increases while the Evenness (E) stayed at a similar level along the downstream longitudinal gradient.

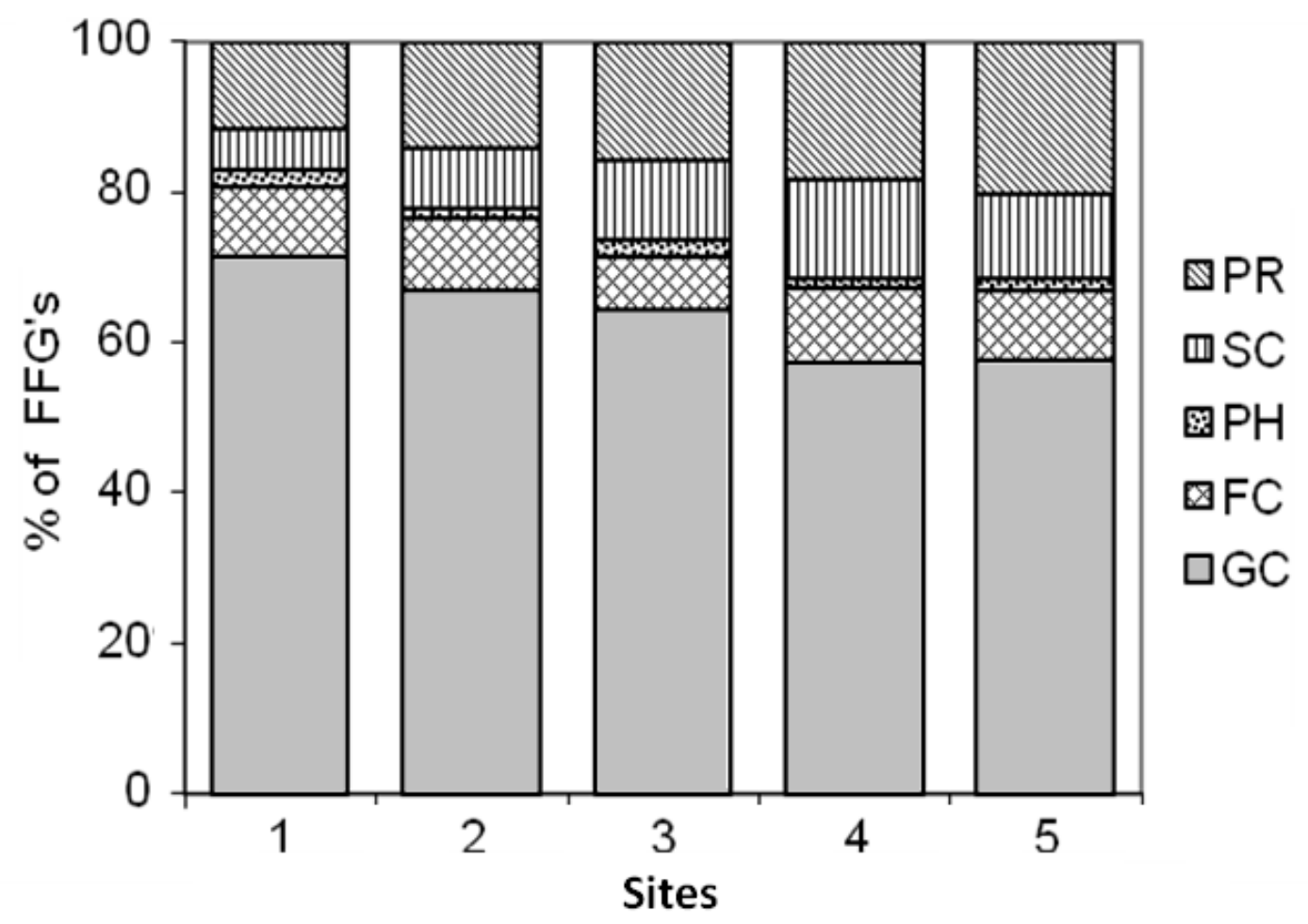

Fig 4 Relative functional feeding groups (FFGs) distribution of colonizing invertebrates in natural leaf packs. $(\mathrm{GC}=$ Gathering Collectors, $\mathrm{FC}=$ Filtering Collectors, $\mathrm{PH}=$ Piercer-Herbivores, $\mathrm{PR}=$ Predators, $\mathrm{SC}=$ Scrapers, $)$.

\section{DISCUSSION}

The results of the investigations, in addition to the decomposition experiment with litter bags in Eswathu Oya, showed the plant composition of natural leaf packs along the longitudinal gradient of the stream and of the invertebrate animals associated with these leaf packs. Comparisons were made of these results of stream fauna investigations in Eswathu Oya, with the decomposition experiment results and with other outcomes from tropical or temperate areas.

In our findings, abundances of colonizing animals in leaf packs increase intensively with the longitudinal gradient of the stream, indicating the longitudinal distribution of the macrozoobenthic fauna in this stream. Our results also show a longitudinal increase of colonizing invertebrate variety in terms of numbers of operational taxonomic units (OTUs) and the Shannon-Wiener index (Fig. 3).

According to the River Continuum Concept (RCC, Vannote et al., 1980), species richness increases from upstream to downstream with the size increase of the stream, and results of the present study corroborate the concept. Analysing the composition of the invertebrate assemblages in natural leaf packs along the Eswathu Oya, Diptera, especially Chironomidae, are the dominating 
Hiranthi Walpola et al.

taxonomic group in the whole of the stream, although a longitudinal pattern is noticeable. Diptera dominate in the whole stream, but decrease in abundance from the headwaters to downstream sites, with approximately similar densities (Fig. 4). The dipterans appear to be the major competitors of coleopterans, as their quotient increases in parallel to the decreasing quotient of Diptera along the stream (Fig. 4). All the other main taxonomic groups such as Trichoptera, Ephemeroptera, Plecoptera or Odonata do not play a conspicuous role and do not show any longitudinal pattern of occurrence. A comparable situation has been recorded in the Tubod River (Leyte, Philippines), where Ephemeroptera are the dominant group, followed by Plecoptera, with maximum abundance in the middle reaches of the stream (Leichtfried at al., 2002).

In the present study, the FFGs analysis was carried out with the available literature from temperate regions (Merritt and Cummins, 1996) and also with available literature from tropical regions (Dudgeon, 1999). Based on this literature, we were unable to find any shredder species in our research area. May be more tropical taxonomic work is needed, in order to be able to identify the tropical macro invertebrates better. However, with higher rates of microbial activity and abundance of biofilms, shredders are not essential in tropical regions for the leaf litter decomposition process, although diversity of leaves in the stream is high. Besides, leaves of most tropical wet zone plants do not have thick epidermis and cuticles which contain complex and large molecules difficult to be broken down unless shredded and the surface area is increased. Further research is required to understand the role of shredders in food webs of tropical streams.

The influence of shredders on leaf breakdown is well known in temperate streams (Graça, 2001), but in tropical streams, both situations are occurring, with and without shredders. Some studies from tropical streams (Irons et al., 1994; Dobson et al., 2002; Dudgeon and $\mathrm{Wu}, 2009$ ) reported that shredders were few, or even absent and therefore did not play important roles in leaf breakdown.

The analysis of Functional Feeding Groups (FFGs) in the natural leaf packs showed, dominance of one group, the 'Gathering Collectors` (Fig. 5). 'Shredders` were absent from all the natural leaf packs investigated. These results were similar to those of $\mathrm{Li}$ and Dudgeon (2009) in Hong Kong streams, Dobson et al. (2002) in Kenyan streams. However, the dominant 'Gathering Collectors' decreased along the river gradient from the headwaters to downstream. The other constituents of the macro-invertebrate community in the stream were 'predators' and. 'scrapers', and their abundance increased along the stream gradient. All other FFGs played no important role in the longitudinal gradient and did not show any longitudinal pattern (Fig. 4). Death (1995) found that macro invertebrate communities in stable sites were higher than those in unstable sites with communities in unstable streams being dominated by mobile collector/browsers. With increase of stream stability, other macroinvertebrate communities tend to increase and dominate, although the dominance by other species does not necessarily lead to removal or reduced densities of mobile collector/ browsers. Our observations in the present study also showed a similar scenario and the relative longitudinal distribution of Chironomidae decreased with the longitudinal gradient allowing other functional groups to occupy the habitat.

As reported by Angermeier (1982), fish can be opportunistic feeders, whenever there is a scarcity of their favourite food, or highly selective when preferred food items are plentiful. It helps to maintain their populations in resource-limited environments such as mountain streams. According to these findings, apparently the invertebrates too are opportunistic feeders like fishes, whenever there is a scarcity of their favourite food.

Current velocity is one of the most important environmental factors controlling communities and processes in streams. However, gradient of the terrain is an important factor that affects current velocity and therefore contributes to the habitat quality, in terms of ease with which macro invertebrate species, may ingest food particles in riffles (e.g. grazers) (Poff et al., 2003). Habitats associated with pools where the current velocity is very low may be ideal for scavenging for food. Our decomposition study was done at a site in extreme headwaters, where pools and riffles were not really developed, hence, velocity effects were negligible here. 


\section{Hiranthi Walpola et al.}

Pielou (1975) reported that the concept of biodiversity (species richness and evenness) is a central theme in community/ecosystem ecology and can be used to explain other ecosystem properties, such as biological productivity, habitat heterogeneity, habitat complexity and disturbance. Species diversities are moderate in stable ecosystems, high in intermediate and low in severely degraded ecosystems (Connell, 1978). According to this classification, our findings show that site 5 , is more stable than the other sites.

\section{ACKNOWLEDGEMENTS}

We are greatly indebted to the Austrian Exchange Service, Agency for International Cooperation in Education and Research (OEAD) in Vienna, for making this study possible. We thank also to the Commission for Development Studies (KEF) for supporting the IRESA Project (Initiative of River Ecology in Sri Lanka: from Science to Application) in Sri Lanka within the framework of which this study was done.

\section{REFERENCES}

Aerts, R. 1997. Climate, leaf litter chemistry and leaf litter decomposition in terrestrial ecosystems: a triangular relationship. Oikos 79: 439-449.

Aderson, W.B. and G.A. Polis 1998. Marine subsidies of island communities in the Gulf of California: evidence from stable carbon and nitrogen isotopes. Oikos 81: 75-80.

Angermeier, P.L. 1982. Resource seasonality and fish diets in an Illinois stream. Environmental Biology of Fishes 7: 251-264.

Benke, A.C., T.C. van Arsdall Jr. and D.M. Gillepie 1984. Invertebrate productivity in a sub-tropical blackwater river: the importance of habitat and life history. Ecological Monographs 54: 25-63.

Baerlocher, F. and B. Kendrick 1975. Leaf conditioning by microorganisms. Oecologia 20: 359-362.

Bradford, M.A., G.M. Tordoff, T. Eggers, T.H. Jones and J.E. Newington 2002. Microbiota, fauna, and mesh size interactions in litter decomposition. Oikos 99: 317-23.
Brown, A.V. and P.B. Brussock 1991. Comparisons of benthic invertebrates between riffles and pools. Hydrobiologia 220: 99-108.

Campbell, I.C. and L. Fuchshuber 1995. Polyphenols, condensed tannins and processing rates of tropical and temperate leaves in an Australian stream. Journal of North American Benthological Society 14: 174-182.

Cheshire, K., L. Boyero and R.G. Pearson 2005. Food webs in tropical Australian streams: shredders are not scarce. Freshwater Biology 50: 748-769.

Chergui, H. and E. Pattèe 1988. The effect of water current on the decomposition of dead leaves and needles. Verhandlungen des Internationalen Verein Limnologie 23: 1294-1298.

Connell, J.H. 1978. Diversity in tropical rain forests and coral reefs. Science 199: 1302-1310.

Cummins, K.W., M.A. Wilzbach, D.M. Gates, J.B. Perry and W.B. Taliaferro 1989. Shredders and riparian vegetation. BioScience 39: 24-30.

Cummins, K.W., R.W. Merritt and P.C.N. Andrade 2005. The use of invertebrate functional groups to characterize ecosystem attributes in selected streams and rivers in south Brazil. Studies on Neotropical Fauna and Environment 40: 69-89.

Dangles, O., M.O. Gessner, F. Guerold and E. Chauvet 2004. Impacts of stream acidification on litter breakdown: implications for assessing ecosystem functioning. Journal of Applied Ecology 41: 365-378.

Danger, A.R. and B.J. Robson 2004. The effects of land use on leaf-litter processing by macroinvertebrates in an Australian temperate coastal stream. Aquatic Sciences 66: 296-304. https://doi.org/10.1007/s00027-004-0718-5

Death, R.G. 1995. Spatial patterns in benthic invertebrate community structure: products of habitat stability or are they habitat specific. Freshwater Biology 33: 455-467.

Dobson, M., A. Magana, J.M. Mathooko and F.K. Ndegwa 2002. Detritivores in Kenyan highland streams: more evidence for the paucity of shredders in the tropics? Freshwater Biology 47: 909-919.

Dudgeon, D. 1999. Tropical Asian Streams: Zoobenthos, Ecology and Conservation. Hong Kong University Press, Hong Kong. 844 p.

Dudgeon, D. 2000. The ecology of tropical Asian rivers and streams in relation to biodiversity 
Hiranthi Walpola et al.

conservation. Annual Review of Ecology, Evolution and Systematics 31: 239-263.

Dudgeon, D. and K.K.Y. Wu 1999. Leaf litter in a tropical stream: food or substrate for macroinvertebrates? Archiv für Hydrobiologie 146: 65-82.

Fernando, C.H. and S.R. Weerawardhane 2002. Sri Lanka freshwater fauna and fisheries. Volumes Publishing, Kitchener. Ontario, Canada.

Findlay, S., M. Carriero, V. Krischik and C.G. Jones 1996. Effects of damage to living plants on leaf litter quality. Ecological Applications 6: 269-275.

Gessner, M.O., E. Chauvet and M. Dobson 1999. A perspective on leaf litter breakdown in streams. Oikos 85: 377-84.

Graça, M.A.S. 2001. The role of invertebrates on leaf litter decomposition in streams - a review. International Review of Hydrobiology 86: 383-393.

Hättenschwiler, S. and P. Gasser 2005. Soil animals alter plant litter diversity effects on decomposition. PNAS USA 102: 1519-1524.

Huxel, G.R. and K. McCann 1998. Food web stability: the influence of trophic flows across habitats. American Naturalist 152: 460-469.

Irons, J.G. III, M.W. Oswood, R.J. Stout and C.M. Pringle 1994. Latitudinal patterns in leaf litter breakdown: is temperature really important? Freshwater Biology 32: 401-411.

Leichtfried, M. 2007. The energy basis of the consumer community in streams yesterday, today and tomorrow. International Review of Hydrobiology 92 (4-5): 363-377.

Leichtfried, M., F. Goeltenboth, Ch. Appel, W.S. Weliange, A. Lang, A. Mazo, R. Omega and J. Pogosa 2002. Investigations of lotic freshwater habitats on the Tubod River, Leyte, Philippines. pp. 1-16. In: Szinicz, G. and F. Goeltenboth (eds) Proceedings of the 9th International Seminar and Workshop on Tropical Ecology, 26 August 09 September 2002, Layte State University, Layte, Philippines.

Li, A.O.Y. and D. Dudgeon 2009. Shredders: species richness, abundance and role in litter breakdown in tropical Hong Kong streams. Journal of North American Benthological Society 28(1): 167-180.

Mathuriau, C. and E. Chauvet 2002. Breakdown of leaf litter in a neotropical stream. Journal of
North American Benthological Society 21: 384396.

Meritt, R.W. and K.W. Cummins 1996. An introduction to aquatic insects of North America. $3^{\text {rd }}$ Edition. Kendall/Hunt Publishing Company, Iowa, USA.

Pearson, R.G., R.K. Tobin, R.E.W. Smith and L.J. Benson 1989. Standing crop and processing of leaf litter in a tropical Australian stream. Archiv für Hydrobiologie 115: 481-98.

Peterson, R.C. and K.W. Cummins 1974. Leaf packs processing in a woodland stream. Freshwater Bioliogy 4: 343-368.

Pielou, E.C. 1975. Ecological Diversity. WileyInterscience, New York, USA.

Polis, G.A. and S.D. Hurd 1996. Allochthonous input across habitats, subsidized consumers, and apparent trophic cascades: examples from the ocean-land interface. pp. 275-285. In: Polis, G.A. and Winemiller, K.O. (eds) Food Webs: integration of patterns and dynamics. Chapman and Hall, New York, USA.

Poff. N.L., T. Wellnitz and J.B. Monroe 2003. Redundancy among three herbivorous insects across an experimental current velocity gradient. Oecologia 134: 262-269.

Richards, C., R.J. Haro, L.B. Johnson and G.E. Host 1997. Catchment and reachscale properties as indicators of macroinvertebrate species traits. Freshwater Biology 37: 219-230.

Rosemond, A.D., C.M. Pringle and A. Ramirez 1998. Macroconsumer effects on insect detritivores and detritus processing in a tropical stream. Freshwater Biology 39: 515-523.

Royer, T.V. and G.W. Minshall 2003. Controls on leaf processing in streams from spatial-scaling and hierarchical perspectives. Journal of North American Benthological Society 22: 352-358.

Sponseller, R.A. and E.F. Benfield 2001. Influences of land use on leaf breakdown in southern Appalachian headwater streams: a multiple-scale analysis. Journal of North American Benthological Society 20: 44-59.

Suberkropp, K. and E. Chauvet 1995. Regulation of leaf breakdown by fungi in streams: influence of water chemistry. Ecology 76: 1433-1445.

Strong, D.R. 1992. Are trophic cascades all wet? Differentiation and donor-control in speciose ecosystems. Ecology 73: 747-754. 
Stockly, R.A., G.S. Oxford and R.F.G. Ormond 1998. Do invertebrates matter? Detrital processing in the River Swale-Ouse. The Science of the Total Environment. 210/211: 427-435.

Swift, M.J., O.W. Heal and J.M. Anderson 1979. Decomposition in Terrestrial Ecosystems. University of California Press, Berkeley, USA.

Vannote, R.L., G.W. Minshall, K.W. Cummins, J.R. Sedell and C.E. Cushing 1980. The river continuum concept. Canadian Journal of Fisheries and Aquatic Sciences 37: 130-137.

Vasconcelos, H.L. and W.F. Laurance 2005. Influence of habitat, litter type, and soil invertebrates on leaf-litter decomposition in a fragmented Amazonian landscape. Oecologia. 144: 456-62.

Wallace, J.B. and J.R. Webster 1996. The role of macroinvertebrates in stream ecosystem function. Annual Review of Entomology 41: 115-139.

Webster, J.R. and E.F. Benfield 1986. Vascular plant breakdown in freshwater ecosystems. Annual Review of Ecology, Evolution and Systematics 17: 567-594.

Whiles, M.R. and J.B. Wallace 1997. Leaf litter decomposition and macroinvertebrate communities in headwater streams draining pine and hardwood catchments. Hydrobiologia 353: 107-119.

Wijenayake, W.M.H.K., Dias, R.K.S. and Chaminda, K.M.G.R. 2001. Population dynamics of the nymphs of Centroptella ceylonensis Muller-Liebenau (Ephemeroptera, Baeridae) in the Aswathu oya, Puwakpitiya. Proceedings of the 10th Annual Scientific sessions of the Sri Lanka Association for Fisheries and Aquatic Resources, Sri Lanka Association for Fisheries and Aquatic Resources, Colombo, Sri Lanka. (Abstract) p.16.

Wright, M.S. and A.P. Covich 2005. The effect of macroinvertebrate exclusion on leaf breakdown rates in a tropical headwater stream. Biotropica 37: 403-408.

Wood, P.J. and P.D. Armitage 1997. Biological effects of fine sediment in the lotic environment. Environmental Management 21: 203-217. 